\title{
Tendencias en la contratación moderna
}

\author{
Atilio Aníbal Alterini
}

\section{Unificación del Derecho Civil y el Derecho Comercial.}

En el Informe que acompañó al Proyecto argentino de Unificación de la Legislación Civil y Comercial, o Proyecto de Código Único, de 1987, se recordó que el Derecho comercial, tal como lo conocemos actualmente, tuvo su origen en la Edad Media, en círcunstancias en las que, en razón de la organización política feudal, el sistema jurídico europeo estaba fragmentado en una gran variedad de estatutos personales que seguían al individuo dondequiera se encontrara. A partir del siglo XI, «apenas la seguridad en los caminos lo permitió, los mercaderes itinerantes se aventuraron cada vez más lejos con sus productos», y se reunieron en ferias en las que participaron comerciantes que provenían de muy diversas regiones y que, por lo tanto, estaban sujetos a sus propias leyes personales. Para posibilitar los negocios, los señores feudales admitieron que las operaciones de los mercaderes no estuvieran sujetas a la ley del lugar de la feria, y que sus controversias fueran resueltas por jueces ad hoc elegidos por ellos mismos. «Y ocurrió entonces que, para resolver esos conflictos, los mercaderes y sus jueces crearon un nombre nuevo, el de Lex Mercatoria, para un Derecho viejo, el jus gentium», cuyos principios fueron «la prevalencia de la intención sobre la forma, el respetode la palabra empeñada o de la promesa formulada, la obligación de soportar equitativamente las ventajas y los daños derivados de sus relaciones patrimoniales, la necesidad de actuar de buena fe con prescindencia de las formas o ritos utilizados».

El Derecho Comercial nació, pues, como una regulación corporativa, con una nota distintiva singular: era personal a quienes ejercían una determinada actividad, era por lo tanto el Derecho de los comerciantes. Estos obtuvieron dos ventajas muy especiales: crearon su propia regulación jurídica, al asignársele fuerza jurídica vinculante a sus propios usos; y designaron sus propios jueces. Porque los señores feudales permitieron y, más aún, garantizaton; que los comerciantes resolvieran entre ellos sus conflictos particulares, con sus reglas específicas. 
En las Codificaciones del siglo XIX se produjo una fuerte expansión del área de vigencia del Derecho Mercantil. La regulación subjetiva fue reemplazada por otra objetiva, que dejó de tomar en cuenta a la persona del comerciante y atendió en cambio a las características de determínados actos, denominados actos de comercio; el Código de Comercio francés de 1807, luego de establecer en el inciso $1^{\circ}$ del artículo 631 -con la concepción subjetiva- que los tribunales de comercio conocerán «los litigios relativos a las obligaciones y transacciones entre cometciantes, mercaderes y banqueros», incorporó también -en el inciso $3^{\circ}$ del mismo artículo y en el artículo 632- la noción de acto de comercio con la concepción objetiva, al referirse a «los actos de comercio entre cualquier persona», y enumerar luego cuáles «reputa actos de comercio». El Código de Comercio alemán de 1861 difundió, a su vez, mediante su artículo 277, el concepto de actos unilateralmente comerciales, comprendiendo de tal modo en la regulación mercantil a los actos en los cuales sólo una de lás partes es comerciante.

Esa expansión se realizó a expensas del Derecho Civil, generando varios inconvenientes que ha reseñado Vivante. Por lo pronto, la delimitación del área de la materia comercial suele ser incierta. Además suele ser artificiosa, pues muchos actos son considerados mercantiles aunque no tengan relación con el comercio en sentido económico, como las letras de cambio. El Código de Comercio nació como un Código de clase para los comerciantes, que deja sin defensa a quienes, sin serlo, quedan sometidos a él pues, desde que los usos comerciales son creados por los propios comerciantes, y tienen efecto jurídicamente vinculante, los no comerciantes están sujetos a normas que frecuentemente ignoran.

En el ensayo titulado «Nacimiento, vida, pasión, muerte y resurrección del Derecho Mercantil», que el Maestro peruano Carlos Torres y Torres Lara publicó hace unos años (en Jus et Praxis, Universidad de Lima, núm. 5, julio de 1985), se explica la evolución del Derecho Comercial conforme a estos criterios:

Su nacimiento -según vimos- se produjo en la Edad Media, como un Derecho «de una clase pobre, marginal y sin importancia a los ojos de sus contemporáneos», la clase de los vendedores ambulantes que no compraban para consumit, sino para vender.

En el tiempo de vida, el Derecho Comercial tuvo esplendor. El comercio se desarrolló expansivamente, los pequeños vendedores ambulantes pasaron a ser ricos comerciantes -formando una nueva clase social, la burguesía, en la que se apoyaron los reyes para imponer su poder a los señores feudales-, y el Derecho Mercantil desplazó al Derecho Civil, cuyas normas «de procedencia romana estaban concebidas para una actividad fundamentalmente privada, familiar e inmobiliaria y de consumo», frente a la cual «el comercio se desarrolló como actividad masiva, mobiliaria y de lucro».

A partir del siglo XVII el Derecho Comercial entró en la época de la pdsión. Una vez que la clase noble y feudal fue dominada con la financiación de los comerciantes burgueses, la monarquía reasumió el poder estatal en la producción de las normas del Derecho Comercial; así, por ejemplo, Luis XIV dictó las denominadas Ordenanzas de Comercio y de Marina de Colbert (años 1673 y 1681). Luego siguieton la Revolución, y el 
terror. Después, Napoleón Bonaparte dictó dos Códigos, el Civil en 1804 y el de Comercio en 1807. El Código Civil toma "perspectiva desde el mundo familiar, inmobiliario y casi estático, ajeno al sentido de lucro y fuertemente influido por los principios de equilibrio, prudencia, ayuda y mutualidad: sacrifica la eficacia y rapidez en busca de la justicia». El Código de Comercio, en cambio, con «la perspectiva de la nueva clase burguesa», está «plasmado de reglas prácticas, utilitarias, de base mobiliaria, y el lucro y no la mutualidad como centro de la acción: sacrifica la justicia en busca de la eficacia y la eficiencia». Además, para evitar que sea un Código clasista -que sería incompatible con la bandera revolucionaria de igualdad-, «se inventa, justifica y luego se defiende, durante casi dos siglos, que el Derecho Comercial se aplicaría, no para los comerciantes como clase, sino para cualquiera que realizara actos comerciales" $y$, al pasar del subjetivismo al objetivismo, «ya no importa quién realiza el acto, sino el acto mismo».

Cuando estalla la Revolución industrial y el comercio se masifica, adviene la muerte del Derecho mercantil. Los Códigos son modificados sustancialmente, ya que «el comercio varía día a día y las necesidades económicas así lo exigen»; pero "no hay tiempo para dictar nuevos Códigos, pues mientras las Comisiones estudian cómo lograr una nueva codificación, el Código sigue siendo modificado por partes». Los Códigos de Comercio, en definitiva, «quedan literalmente descuartizados». Así ha sucedido en Argentina: en la Introducción a las Notas Explicativas del Proyecto de Código Unico de 1987 fue señalado que «lo que hoy se conoce como Código de Comercio es, principalmente, la presentación conjunta de una variedad de leyes especiales». Lo único que las une es la encuadernación.

Pero entonces se produce la resurrección del Derecho Comercial, aunque «en una nueva forma, aún más fuerte que antes», pues «sus reglas ya no están necesariamente en un Código de Comercio, sino que ahora se incorporan al Código Civil y éste deja sus antiguas vestiduras: al igual que ciertas costumbres bárbaras se incorporaron a la civilización occidental y viven aún hoy habiéndose puesto el nuevo ropaje de la cultura occidental, así el Derecho Mercantil, con ropaje civil, se ha impuesto en las nuevas sociedades», bajo la forma del denominado Derecho Privado, o Derecho Privado Patrimonial. Se ha producido la comercialización del Derecho Civil -antes bien que la civilización del Derecho Comercial-, en razón de «la masificación de la nueva sociedad, en la que todos o casi todos actuamos en las actividades mercantiles, tomadas éstas en su sentido más genérico, es decir, como actividad económica».

En la nueva categoría del Derecho Privado Patrimonial -lo señala Polo- «el Derecho Privado y el Derecho Público se relacionan e influyen recíprocamente en este tema hasta tal punto que raro es el sector o parcela de la problemática jurídica cuyo tratamiento exija sólo normas de uno u otro carácter», por lo cual -completa Bercovitz- «el Derecho mercantil tiene que ser sustituido por un Derecho Privado del tráfico económico».

La división entre el Derecho Civil, propio de la Economía agrícola, y el Derecho Comercial, propio del comercio y de la industria (Ascarelli), se diluyó y perdió sentido. La comercialización del Derecho Civil es, pues, el resultado de varias causas, que precisa Broseta Pons: el trasvasamiento de criterios comerciales al Derecho Civil; la «difusión del espíritu 
comercial» de que habla Garrigues, la cual se patentiza, por ejemplo, por la generalización de las operaciones de banco y de los títulos de crédito; la prevalencia de las normas propias de los contratos comerciales sobre las correspondientes a los civiles; la modalidad de contratación en masa.

Hace sesenta años, Ripert describió con precisión cómo se han expandido actualmente los actos mercantiles: «Los actos de la vida corriente son realizados hoy día bajo la forma comercial. El contrato no es más un acuerdo concluido después de una larga discusión, con redacción de un escrito en doble ejemplar. Es adhesión a cláusulas predispuestas, impresas en formulario, la compra de un billete a precio fijo, la inscripción en un registro. La misma vida rural no escapa a esa comercialización. Conoce el crédito agrícola y el warrant de la cosecha, la expedición de mercaderías por el ferrocarril y el pago de las facturas mediante letras». Una persona que no adquiera ningún inmueble puede pasar la vida sin acudir a una escribanía; pero no puede dejar de acudir, hasta cotidianamente, a un banco.

Para determinar si la unificación se ha producido, es una tarea útil explorar si, en un determinado sistema jurídico, se dan los indicadores que destaca Rotondi. Ellos son la incorporación al Código Civil de los principios propios de los contratos comerciales: por ejemplo, la doctrina de la apariencia, la fuerza jurígena de los usos, la interpretación conforme a la buena fe-probidad, la mora automática, la cláusula resolutoria tácita, el anatocismo. El sometimiento del concurso de los no comerciantes a igual procedimiento que el aplicado a los comerciantes, y la sujeción al juez mercantil. Los particularismos de la legislación de la navegación. La generalización de los títulos valores. Todos esos indicadores se dan claramente en Argentina, en especial porque el Código Civil recogió la mayoría de los principios mercantiles a través de la reforma que le introdujo la ley 17.711 en el año 1968.

Hamel distingue la unificación sustancial de la fusión formal. Aquella se da cuando existe un Derecho unificado. Esta, cuando se dicta un Código único comprensivo de la materia civil y de la materia comercial, caso en el cual puede haber -diría Brunetti-, «en lugar de una obra de dos tomos, un solo tomo para dos obras». En Argentina hemos procurado, mediante la fusión formal, denotar la unificación sustancial que, en los hechos, en el Derecho vivo, se ha producido hace tiempo. El 18 de diciembre de 1998 la Comisión honoraria que integramos con los profesores doctores Héctor Alegría, Jorge Horacio Alterini, María Josefä Méndez Costa, Julio César Rivera y Horacio Roitman, presentó un Proyecto de Código Civil unificado con el Código de Comercio, de 2532 artículos.

Seguimos así una fuerte corriente del Derecho comparado, iniciada por el Código suizo de las obligaciones - a partir del año 1881- que fue incorporado como Libro $V$ del Código Civil en 1912. También fue aceptada por Túnez (1906), Marruecos (1912), Turquía (1926), Líbano (1934), Polonia (1934), Madagascar (1966), Senegal (1967) y, comprendiendo materia civil y comercial, por los códigos civiles de Italia (1942), Unión Soviética (1964), Perú (1984), Paraguay (1987), Cuba (1988), Holanda (1992), Mongolia (1994), Federación Rusa (1994), Vietnam (1995), así como por los Códigos únicos en lo 
civil y comercial de China (Taiwán) y del reino de Tailandia, y por los Principios generales del Derecho Civil de la República Popular China, de 1987. El Código Civil de Québec de 1992 y el Código Civil de Holanda del mismo año transitan un camino semejante, en especial en cuanto introducen regulaciones propias del Derecho del consumo. En el sistema anglonorteamericano la unificación rige desde el siglo XVIII, con dos características particulares: las reglas comerciales predominan por sobre las civiles, y subsisten normas especiales para ciertas figuras mercantiles.

\section{Obtención de una lingua franca para el comercio internacional.}

El fenómeno de la unificación de las regulaciones correspondientes a los contratos civiles y a los contratos comerciales tiene particular vigencia en el Derecho de la Unión Europea, con varias importantes expresiones del propósito de obtener una lingua franca común en materia de contratos; es de recordar que, ya a principios de 1888, Cesare Vivante presentó en Parma su trabajo Per un codice unico delle obligazioni, y que el Proyecto franco-italiano de 1927 fue un importante intento tendiente a los mismos fines. En los proyectos actuales se lleva adelante la idea unificadora, con un tono tan intenso que han aparecido importantes revistas jurídicas especializadas: la Zeitschrift fur Europaisches Privatrecht en Alemania, y la European Review of Private Law en Holanda.

En la Nota de Elevación del Proyecto de Código Civil de 1998 señalamos varios antecedentes relevantes, que fueron tenidos especialmente en cuenta al redactarlo. Son éstos.

a) El Contract Code de McGregor. El profesor de Oxford y de Londres Harvey McGregor recibió en 1966 el encargo de la Law Commission británica de preparar un proyecto de Código de Contratos. Lo concluyó en 1971, y fue publicado tardíamente (Contract Code: drawn up on behalf of the English Law Commission, Londres, 1994; en traducción española de de la Cuesta Sáenz, J. M. y Vattier Fuenzalida, C., Contract Code. Proyecto redactado por encargo de la Law Commision inglesa, Barcelona, 1996). Según expresa su autor en el Prólogo, contiene una «recopilación desde la óptica del Common Law», esto es, se trata de una compilación o consolidación del Derecho que rige en Gran Bretaña, basado fundamentalmente en la jurisprudencia, que pretende aproximar sus soluciones a las del Derecho continental.

b) El Anteproyecto de Código Europeo de Contratos. La Academia de Jusprivatistas Europeos, integrada por prestigiosísimos profesores pertenecientes a los sistemas del Derecho continental y del Common Law, realizó una serie de coloquios en Pavía (Italia) a partirde 1990, de los cuales surgió la constitución de un Grupo de Trabajo -integrado poralrededor de setenta juristas, de todos los países europeos, incluyendo a los presidentes de las respectivas cortes supremas - que elaboró el Anteproyecto de Código Europeo de Contratos con el cual, como se lee en el Preámbulo, se pretende lograr un «Código nuevo, cuyo texto y contenido estén en armonía con las circunstancias socio-económicas actuales», y "mantener la unificación entre el Derecho Civil y el Derecho Comercial". El Grupo de Trabajo tomó 
como esquema de base el Código Civil italiano -por considerarlo intermediario entre los grandes sistemas francés y alemán, y por la unificación del Derecho Civil y el Derecho Comercial que contiene-, y el ya mencionado Contract Code de McGregor. En el Preámbulo del Anteproyecto también se expresa haber «decidido mantener la unificación entre Derecho Civil y Derecho Comercial, que ha sido realizada por el Código italiano, ha sido seguida en otros países del continente, y está presente en sustancia en la experiencia del Common Law». La primera parte del Anteproyecto se conoció en octubre de 1995, y la segunda, en marzo de 1997.

c) Los Principios del Derecho Europeo de Contratos. El 26 de mayo de 1989 -y el 6 de mayo de 1994- el Parlamento Europeo encargó al profesor de Copenhague Ole Landö la redacción de un Código Europeo de Derecho Común de Contratos. Integró una Comisión con una veintena de destacados juristas europeos, y dio a conocer la versión final de los Principios del Derecho Europeo de Contratos en julio de 1998.

d) Los Principios sobre los Contratos Comerciales Internacionales de UNIDROIT. UNIDROIT (Instituto Internacional para la Unificación del Derecho Privado), Organización no Gubernamental con sede en Roma, dio a conocer en 1994 los Principios sobre los Contratos Comerciales Internacionales, que fueron elaborados por un Grupo de trabajo que integraron profesores, magistrados y funcionarios de alto rango, pertenecientes a los principales sistemas jurídicos de todo el mundo. Su Introducción expresa que «el objetivo de los Principios de UNIDROIT es establecer un conjunto equilibrado de reglas destinadas a ser utilizadas en todo el mundo, independientemente de las específicas condiciones económicas y políticas de los países en que vengan aplicados». Del Preámbulo resulta que los Principios se propusieron establecer «reglas generales aplicables a los contratos mercantiles internacionales» y actuar como «principios generales del Derecho» o como «Lex Mercatoria», así como «servir de modelo para la legislación a nivel nacional o internacional» o para ser utilizados por los particulares en los «contratos estrictamente internos o nacionales»; sólo se ha pretendido «excluir del ámbito de los Principios las llamadas 'operaciones de consumo'".

e) La Convención de Viena de 1980 sobre Compraventa Intemacional de Mercaderías. UNCITRAL, esto es la Comisión de las Naciones Unidas para el Desarrollo Mercantil Internacional, elaboró la Convención de Viena de 1980 sobre Compraventa Internacional de Mercaderías, que Argentina ratificó por ley 22.765. Rige en cincuenta y un países, y este número se amplía: desde el 1 de enero de 1999 es aplicable en Mongolia y en Grecia, desde el 10 de octubre de 1999 lo será en Burundi, y desde el 1 de enero del 2000, en Uruguay. La incorporación de esa Convención al Derecho interno de los países periféricos que la ratificaron tiene particular importancia en materia contractual, pues introduce diversas soluciones propias del Derecho de los más desarrollados, que se reflejan también en los ya mencionados Principios de UNIDROIT, en el Anteproyecto de Código Europeo de Contratos y en los Principios del Derecho Europeo de Contratos. 


\section{Desplazamiento de los pivotes de la teoría del contrato.}

Dice Alpa, citando a Kronman, que los pivotes de la teoría tradicional, o clásica, del contrato, fueron tres: individualizar qué acuerdos son vinculantes, precisar los derechos y los deberes que nacen del acuerdo, y prever las consecuencias del incumplimiento culpable.

Esos pilares han sido jaqueados. En la actualidad, la virtualidad jurídica del duonum vel plurium in placitum consensus, como resultado de una negociación pas à pas o de gres à gres, ha sido extendida al proteger la confianza generada por cierta conducta antes bien que la sacralidad del pacto, al asignársele virtualidad jurígena a la oferta, a ciertos comportamientos no declarativos, a los acuerdos parciales. Estos, aceptados en el Código Civil alemán (\$ 54) y en el Código de las Obligaciones suizo (artículo 2), reaparecen en la Convención de Viena de 1980 sobre Compraventa Intemacional de Mercaderías (artículos 14.1 y 19.2$)$.

La determinación de las obligaciones que resultan del contrato ha sido extendida mediante la incorporación de los deberes secundarios de conducta emanados de la regla de buena fe. Actualmente, interpretar un contrato no es solamente entender sus cláusulas oscuras, sino integrarlo con esa regla vital del sistema, sin que su literalidad encorsete las reglas de conducta exigibles. En tal sentido, el Proyecto de Código Civil argentino de 1998 dispone que en la interpretación es preciso atender a estas directivas: "El contrato obliga con los alcances en que razonablemente se habría obligado un contratante cuidadoso y previsor, incluyendo a las consecuencias virtualmente comprendidas en él, conforme a su naturaleza, a las negociaciones previas, a la conducta ulterior de las partes, a las prácticas establecidas entre ellas, a los usos si no han sido excluidos expresamente, y a la equidad, teniendo en cuenta la finalidad del acto y las expectativas justificadas de la otra parte" (artículos 1023 y 967).

La responsabilidad contractual no está confinada a la culpa, pues en su ámbito hay muchas hipótesis de responsabilidad objetiva, algunas de las cuales han existido en el sistema desde siempre -como la del transportista, o la del hotelero-, y últimamente se las ha descubierto. Pero hay un criterio de modulación, al redefinir el caso fortuito, y al no exigir imperativamente que promedie una catástrofe para tenerlo por configurado, como lo hace con especial brillo la doctrina italiana. En zona conceptual afín, aparece la noción de impedimento ajeno a la voluntad del deudor, que resulta de la Convención de Viena de 1980 sobre Compraventa Internacional de Mercaderías. Su artículo 79 dispone que el deudor «no será responsable de la falta de cumplimiento de cualquiera de sus obligaciones si prueba que esa falta de cumplimiento se debe a un impedimento ajeno a su voluntad y si no cabría razonablemente esperar que tuviese en cuenta el impedimento en el momento de la celebración del contrato, que lo evitase o superase o que evitase o superase sus consecuencias». Igual criterio siguen los Principios de UNIDROIT (artículo 7.1.7 [1]). En esa misma dirección, en el Derecho norteamericano le es otorgada al deudor la posibilidad de desligarse si la prestación resulta impracticable sin su culpa por un hechocuya inexistencia 
fue asumida como básica para contratar (Restatement of Contracts 2 nd., § 261; Uniform Commercial Code, Sec. 2.615). A su vez, el concepto de impracticabilidad es entendido con mayor extensión que el de imposibilidad (que es propio del caso fortuito en sentido estricto), pues abarca hipótesis en las cuales, no obstante los esfuerzos razonables que le son exigibles, el deudor no ha podido superar dificultades cxtremas y no razonables, o el cumplimiento le habría ocasionado gastos, daños o pérdidas desproporcionados (Restatement of Contracts 2nd., § 205). Concordantemente, el Proyecto de Código Civil argentino de 1998 establece que "se considera ajeno a la voluntad del deudor el impedimento que, sin configurar caso fortuito, no puede ser evitado, superado, o resistido, mediante el empleo de la diligencia exigible en las circunstancias propias de la relación contractual" (artículo 1614) y, a causa de él, "el deudor de la obligación queda eximido del cumplimiento, y no es responsable del daño que el incumplimiento causa al acreedor" (artículo 1615).

En sintesis: muchas veces se prescinde de la culpa (en la responsabilidad contractual objetiva) pero, a la vez, la conducta diligente en las circunstancias del caso (la conducta obrada sin culpa) suele liberat al deudor.

\section{El paradigma de libertad negocial.}

Es notorio el reverdecer de la autonomía de la voluntad. El denominado dogma de la autonomía de la voluntad o de la autonomía privada es considerado en Argentina "un principio general del Derecho, de fuente constitucional» (XVI Jornadas Nacionales de Derecho Civil, Buenos Aires, 1997). Coincidentemente, en doctrina francesa moderna se le atribuye ser «uno de los fundamentos del orden civil» (Comú), con valor de «principio» (Carbonnier), y se afirma que eel consentimiento sigue siendo el elemento primordial creador de obligación» (Mazeaud-Chabas). Aún admitiendo la existencia de un «flujo y reflujo» en la autonomía de la voluntad (Malurie-Aynès), y que ella "no es absoluta», se sostiene sin embargo que «sigue siendo la regla» (Flour-Aubert), y que su titulada crisis «no se manifestará, sin dudas, por una desaparición definitiva de este principio» (Larroumet). Se advierte también que en los últimos años «resulta evidentemente un rebrote de eficacia" de ella (Bénabent).

Los Principios de UNIDROIT establecen claramente que «las partes tienen libertad para celebrar un contrato y determinar su contenido» (artículo 1.1), pues -como se explica en su comentatio - «la libertad de contratar constituye el eje sobre el cual gita un orden económico Internacional abierto, orientado hacia el libre comercio y la competitividad», No obstante, dejan a salvo las leyes imperativas (artículo 1.4), como las antimonopólicas, las que prohiben cláusulas abusivas, etcétera. El mismo criterio resulta del Anteproyecto de Código Europeo de Contratos (artículo 2) y de los Principios del Derecho Europeo de Contratos (artículo 1.102).

El mencionado Proyecto argentino, siguiendo al Código Civil quebequés de 1992 (artículo 1372), exalta también la fuerza jurígena del contrato, pues dispone "Son fuentes de las obligaciones: a) Los contratos. b) Las demás relaciones y situaciones jurídicas a las 
cuales la ley les asigna esse carácter" (artículo 672). Los contratos, y lo demás, que resulta ser una especie de etcétera de un centro causal que es puesto en la contratación.

Ahora bien. Junto a la regla de libertad se asienta la máxima de justicia. Libertad con justicia es el reclamo candente que el sistema jurídico de estos tiempos está precisado a satisfacer. Siguen siendo útiles las herramientas tradicionales: el impedimento para obrar abusivamente, la lesión, la imprevisión. Sugiero, sin embargo, que es preciso extender los alcances de la lesión, para adecuarlos a las realidades negociales modernas: así, el artículo 327 del Proyecto argentino de 1998 prevé: "Puede demandarse la invalidez o la modificación del acto jurídico cuando una de las partes obtiene una ventaja patrimonial notablemente desproporcionada y sin justificación, explotando la necesidad, la inexperiencia, la ligereza, la condición económica, social o cultural que condujo a la incomprensión del alcance de las obligaciones, la avanzada edad, o el sometimiento de la otra a su poder resultante de la autoridad que ejerce sobre ella o de una relación de confianza". De tal modo se protege al valetudinario, que no ha tenido ni necesidad, ni inexperiencia, ni ligereza; se toma en cuenta la realidad de las disminuciones del poder negocial que resultan de situaciones socio económico culturales; se incluyen al temor reverencial y al abuso de conftanza.

En esta expansión han tenido fuerte influencia los criterios anglonorteamericanos. Se trata de la teoría de la influencia injusta (Undue Influence), que wllena el nicho entre la incapacidad y la intimidación (duress)» (Schaber-Rohwer), y da lugar a la invalidez del acto. Comprende hipótesis de temor reverencial -que en el Derecho continental, conforme al criterio del artículo 1114 del Código Civil francés, no tiene virtualidad-, pues considera inválido al contrato injusto resultante del ejercicio del poder de persuasión sobre una persona respecto de la cual el persuasor tiene autoridad, o que por la relación de confianza entre ambas hubo de suponer justificadamente que aquél no habría actuado de manera contraria a su bienestar (Restatemient of Contracts 2 nd., $\$ 177$ ).

A su vez, en el Uniform Commercial Code (sec. 2.302) y en el Restatement of Contracts 2nd. ( $\$ 208$ ), es contemplada la categoría genérica de contrato injusto o irrazonable (Unconscionable Contract), entendiéndose tal al que no habría sido celebrado entre ningún hombre que hubiera actuado juiciosamente y sin error, y ningún hombre honesto y justo; o, dicho de otro modo, al que «sacude la conciencia» ( «shocks the conscience») del tribunal, según fórmula tradicional plasmada por Lord Eldon en 1804. Tal contrato es reajustable, y «la grosera disparidad entre los valores intercambiados» constituye evidencia importante para su caracterización (Restatement of Contracts 2 nd., $\$ 208$, comentarios a y c).

\section{Restauraciones de la libertad negocial ante la debilidad jurídica.}

Vuelvo a mostrar la experiencia argentina reciente, que resulta del ya mencionado Proyecto de Código Civil de 1998.

La doctrina sostiene, como resulta de las recomendaciones de las XVI Jornadas Nacionales de Derecho Civil realizadas en Buenos Aires en 1997, que en los contratos 
discrecionales, o paritarios, cuyas partes se encuentran en situación de igualdad jurídica, «rige la plena autonomía privada (artículo 1197, Código Civil), con las limitaciones clásicas». Así debe ser, y estas cortapisas resultan de la concertación sobre objetos prohibidos o inidóneos, de la finalidad ilícita o inmoral del acto, de la transgresión de normas de orden público, y acaso normas solamente imperativas como las que conciernen al vicio de lesión.

En el otro extremo conceptual están los contratos de consumo, en cuya regulación estatutaria sobresale el orden público económico, sea de protección, sea de coordinación. En éstos, el régimen tuitivo se establece en favor de una parte (el consumidor), a cuyo fin la ley fija un mínimo o un máximo de protección, que puede ser dejado de lado siempre que sea a favor de la parte protegida. Esta parte protegida -con palabras de Ripert-pasa a ser «dueña del contrato», en tanto la otra es forzada a cumplir aunque el contrato le resulte desventajoso, y no puede exigir el cumplimiento a pesar de que tenga interés en él. En esa dirección conceptual, la ley argentina establece que, en su caso, el consumidor tiene derecho a optar entre demandar la nulidad total «del contrato, o la de una o más cláusulas» (art. 37, ley 24.240).

Pero, dentro del sistema del Derecho común, hay contratos predispuestos y contratos celebrados por adhesión. En el contrato predispuesto, sus estipulaciones han sido determinadas unilateralmente por alguna de las partes (conf. Directiva del Consejo de la Comunidad Europea CEE 93/13 del 5 de abril de 1993, artículo 3.2); en el celebrado por adhesión, hay un contrato predispuesto en el que la parte no predisponente ha estado precisada a declarar su aceptación (conf. Código Civil peruano de 1984, artículo 1390; Código Civil quebequés de 1992, artículo 1379).

El Proyecto argentino de 1998 se ocupa de una y de otra categoría. Su artículo 968 - con criterios que fueron anticipados por el Proyecto de Código Unico de 1987-dispone que "En los contratos predispuestos se tienen por no convenidas las estipulaciones que, por si solas o combinadas con otras: a) Desnaturalizan las obligaciones de las partes. b) Limitan la responsabilidad del predisponente por daños al proyecto de vida. c) Limitan la responsabilidad del predisponente por daños patrimoniales sin una adecuada equivalencia económica. d) Importan renuncia o restricción a los derechos del no predisponente, $o$ ampliación de los derechos del predisponente, que resultan de normas supletorias. e) Obligan al no predisponente a pagar intereses, si su tasa excede sin justificación y desproporcionadamente el costo del dinero para deudores en operaciones similares". Su artículo 969 admite como excepción que, bajo ciertas circunstancias, tales cláusulas sean aceptadas por el no predisponente, siempre que no se trate de la desnaturalización de la obligación ni del daño al proyecto de vida. Pero su artículo 970 es terminante: "Si el contrato predispuesto ha sido celebrado por adhesión no rigen las excepciones previstas en el artículo anterior", por lo cual todas esas cláusulas son irremediablemente ineficaces. 


\section{Concluyendo.}

La Constitución política peruana de 1993, en la literalidad de su artículo 62, llega a desdibujar la fuerza jurígena del orden público frente a la autonomía de la voluntad, al establecer que rigen «las normas vigentes al tiempo del contrato», y que «los términos contractuales no pueden ser modificados por leyes u otras disposiciones de cualquier clase» dictadas con ulterioridad. Juan Bautista Alberdi, con referencia a la Constitución Argentina de 1853, decía que, «en medio del ruido de la independencia de América y en vísperas de la Revolución francesa de 1789, Adam Smith proclamó la omnipotencia y la dignidad del trabajo; del trabajo libre, del trabajo en todas sus aplicaciones -agricultura, comercio, fábricas - como el principio esencial de toda riqueza», y que «a esta escuela de libertad pertenece la doctrina económica de la Constitución Argentina».

La libertad negocial resulta, pues, adecuada a nuestras Constituciones, y comporta una tendencia nítida de la teoría moderna del contrato. Hasta los Códigos Civiles de países que pertenecían al Mundo socialista dictados en la década de los noventas la respetan puntualmente. Más aun, la propiedad privada que, junto al contrato, es prerrequisito de la economía de mercado, fue aceptada en China continental en marzo de 1999 ,

Otra fuerte tendencia es la superación de preconceptos que han postergado el reconocimiento legislativo de la unificación de los contratos civiles y de los contratos comerciales, que hace mucho se ha producido en el Derecho vivo, es decir, en el que se desembaraza vivificantemente de los cadáveres de los objetos culturales.

Sin embargo, aquella libertad, en el marco de esta unificación, no significa de ninguna manera que todos los criterios mercantiles reinen soberanos. Ha habido un camino de dos vías, que suele diluir algunos de los efectos de la incorporación al Derecho común de principios mercantiles: la exigencia de autorregulación de los comerciantes es contenida por la expansión de las reglamentaciones del contrato para cuidar de los intereses del consumidor; la máxima libertad de formas tiene como contrapartida cierto renacimiento del formalismo tendiente a la debida información de los particulares; la celeridad del comercio es limitada por la existencia de contratos en los que la ley pone el consentimiento en ralenti como una «protección contra las tentaciones» (Malinvaud).

Hay actos que obligan, en alcances idénticos a los del contrato, pese a que no comportan un acuerdo en el sentido clásico. Los deberes de conducta son ensanchados por aplicación de la regla de buena fe, cuya vigencia es afirmada por ser esencial al tráfico mercantil. Se admite la responsabilidad contractual objetiva, pero simultáneamente se exalta la idea de que el incumplimiento obrado sin culpa no genera responsabilidad.

Sobresale también, y fundamentalmente, la exigencia de justicia contractual, cuyo servicio se obtiene, por una parte, reconociendo la fuerza jurígena del albedrío de quienes contratan entre sí en circunstancias de igualdad, con un bargaining power igual o parecido; y, por la otra, estableciendo un adecuado régimen tuitivo -con distintos niveles de intensidad en los contratos de consumo, en los contratos predispuestos y en los contratos celebrados por adhesión. 
El Derecho maduro del Mundo del mercado no es ontológicamente perverso; hemos visto cómo el sistema anglonorteamericano suministra uno y otro mecanismo para lograr esa justicia. La tendencia deseable es que el mercado - que dejó de estar subordinado a la «mano de la burocracia» de Chandler y fue librado a su suerte con la «mano mágica» de Smith- llegue a estas regiones llevando en su mochila dichos mecanismos de control, para enriquecer a los que son clásicos en sus sistemas.

Un reclamo generalizado de seguridad jurídica ha de impulsar fuertemente la tendencia a la unificación internacional de la regulación jurídica de los contratos. Sea con el modelo de los restatements no vinculantes, que siguen los Principios sobre los Contratos Comerciales Internacionales de UNIDROIT y los Principios del Derecho Europeo de Contratos de la Comisión Landö, sea con la idea de suministrar normas vinculantes, como lo hacen la Convención de Viena de 1980 sobre Compraventa Internacional de Mercaderías, el Contract Code de McGregor, y el Anteproyecto de Código Europeo de Contratos de la Comisión Gandolfi.

Pero todas las tendencias modernas en materia contractual sólo serán valiosas si respetan cabalmente a la persona humana pues -se expresa en los Fundamentos del Proyecto argentino de Código Civil de 1998. "El Derecho se hace para la persona, que constituye su centro y su fin; es la misma idea definitoria de la ideología del Código Civil peruano de 1984. Dichas tendencias sólo serán valiosas si logran el desiderátum del bien común, armonizando lo que es bueno para cada uno con lo que es bueno para la generalidad.

Ello, como decía nuestro Martín Fierro en la última estrofa de su canto, «No es para mal de ninguno / Sinó para bien de todos». 